\title{
Viajantes italianos, imigração e italianidade no Brasil
}

\author{
Italian travelers, immigration and italianity in Brazil
}

Núncia Santoro de Constantino*

Resumo: Na segunda década do século XX, portanto após o final da Primeira Grande Guerra, viajantes italianos como D'Atri, Bianco, Bonacci, Carrara e Bortolotti visitaram o Brasil e publicaram livros, pretendendo dar conta de suas "impressões" sobre o país. Justificando seus pontos de vista sobre a imigração italiana, fornecem dados à compreensão do fenômeno, por vezes destacando a questão da italianidade, visto ser a mesma por eles desejada. Assim, o estudo pretende analisar aspectos da vida dos imigrantes em cidades brasileiras, entre 1910 e 1926, e as estratégias desenvolvidas para a construção e manutenção de uma identidade entre imigrantes italianos, a partir da palavra desses viajantes-escritores. Palavras-chave: Viajantes italianos. Imigração urbana. Etnicidade.

Abstract: In the second decade of the twentieth century, so after the end of World War I, Italian travelers as D'Atri, Bianco, Bonacci, Carrara and Bortolotti visited Brazil and published books, intending to register their "impressions" about the country. Justifying their points of view on Italian immigration, they provide data for understanding the phenomenon, sometimes highlighting the question of Italianity, the same as they desire. Thus, the study aims to examine aspects of the life of immigrants in Brazilian cities, between 1910 and 1926, and the strategies developed for building and maintaining an identity among Italian immigrants, from the words written by these traveler-writers.

Keywords: Italian travelers. Inmigrants in brazilian cities. Ethnicity.

* Licenciada em História pela PUCRS, onde realizou o mestrado em Educação; na Universidade de São Paulo realizou o doutorado. Desenvolveu pós-doutorado na Università degli Studi di Torino, Itália, desenvolvendo pesquisa sobre relatos de viajantes italianos no Brasil. Desde 1975 é docente da PUCRS, sendo professora titular do Departamento de História e Pós-Graduação. 
Nas duas últimas décadas do século XIX um amplo debate acompanhou a questão da emigração italiana. Ainda que a corrente favorável a essa emigração fosse mais poderosa e obtivesse grandes vantagens, destacava-se na imprensa a opinião dos socialistas, radicalmente contrários. Os relatos de viagem, literatura de grande alcance, repercutiam quase sempre contrários ao Brasil. O discurso negativo era largamente predominante e os textos enfatizaram os males que afligiam o país, as deploráveis condições para imigrantes, assim como as más características dos brasileiros. Dentre estes textos, são bem conhecidos aqueles de Lomonaco (1889), Macola (1894) e Moriconi (1897), que publicaram livros entre 1889 e 1897.

Por outro lado, o governo italiano mostrava pouquíssimo interesse pela sorte dos compatriotas no Brasil, apesar das contínuas e alarmantes denúncias que se intensificaram desde a metade da década de 1880, relacionadas sobretudo às condições dos imigrantes nas fazendas paulistas de café. Mesmo assim, a plena liberdade de emigrar foi ratificada pela lei de 1888 que vigorou até o alvorecer do século XX. Dessa forma, os governantes italianos livraram-se do excedente populacional e, durante muito tempo, continuaram a ver nos imigrantes cidadãos de segunda categoria.

Entretanto, uma transformação surpreende o pesquisador. Nos últimos anos do século XIX, a opinião favorável à imigração para o Brasil ganha força na Itália, expressando-se nas mudanças de legislação que se verificaram em 1901, quando foi criado um comissariado para a emigração. A Itália estava sendo há algum tempo beneficiada pelas remessas financeiras provenientes dos súditos no exterior. Acreditou-se que esses súditos precisavam ser acompanhados de perto, pois com frequência solicitavam naturalizações. Temia-se que, renunciando à pátria-mãe, fosse interrompido o fluxo de remessas e diminuído o consumo de artigos italianos nas comunidades do exterior. Como escreve Trento (1988, p. 33-37), a preservação da italianidade foi sempre uma preocupação das autoridades italianas. Sob a alegação de tutelar o imigrante e mantê-lo unido à pátria-mãe, havia interesses econômicos por parte dos dirigentes peninsulares.

A transformação na forma de tratar o imigrante seria ainda mais acelerada no período de ascensão do fascismo, quando são robustas as lideranças italianas no Brasil, contaminadas pela ação da diplomacia. Naquelas primeiras décadas do século XX, é fortalecido o mito da Roma Imperial, valorizam-se os feitos dos navegadores italianos, glorifica-se a arte, a filosofia e a literatura renascentista. 
Nas duas primeiras décadas do século XX, alguns viajantes italianos visitaram o Brasil e publicaram livros, pretendendo dar conta de suas "impressões" sobre o país e sobre os imigrantes. Foram impressões altamente positivas, a refletir as mudanças na política para o exterior, a justificar seus pontos de vista favoráveis à imigração italiana. $\mathrm{O}$ presente estudo pretende destacar e comentar aspectos da narrativa desses viajantes, entre 1910 e 1926.

Para tanto, são necessárias algumas generalidades sobre a literatura de viagem como fonte histórica, pois é hora de revisitar o assunto com outros olhos que são aqueles do nosso presente, quando se encontram aperfeiçoadas as metodologias de análise, ajudando a desconstruir discursos, a produzir novas inferências, enfim a produzir um olhar diferente.

Sabe-se que os relatos publicados alcançaram amplo público, a exemplo do que acontecia com a literatura de viagem em geral, porque o caráter descritivo e informativo dos textos comunicava e comunica pelo estilo simples e conciso. Por outro lado, esses escritores-viajantes descrevem o extravagante ou o exótico, que aguça o apetite dos leitores desde muitos séculos.

Vale lembrar que os relatos que menciono são relacionados ao início do século XX, significando respostas a necessidades definidas, como a exigência de uma aculturação científica, do imaginário típico de uma nova mentalidade voltada à modernização e ao progresso (Cattarulla, n. 4 e 5,1992$)$.

Leed examina os momentos cruciais da viagem: partir, transitar, chegar. Exemplifica a importância da mesma viagem lembrando as metáforas que suscita: morte é passagem, passamento, enfim, mobilidade ou deslocamento para regiões desconhecidas. Vida é trajetória, caminho, peregrinação. Viagem, vida e morte são deslocamentos (Leed, 1992, p. 36).

Mencionando metáforas, lembra-se de esclarecer sobre a visão e sobre o olhar de viajantes, que Sérgio Cardoso diferencia de forma consistente, assinalando respectivamente superficialidade e intensidade. A visão é superficial, o olhar é mais profundo. São duas metáforas adequadas ao estudo de lugares longínquos, cidades distantes porque são, antes de tudo, experiências visuais. Como é visual e adequada também a impressão; lembrando que há um manancial de publicações sobre impressões de viagem (Cardoso, 1988).

O viajante olhando auxilia o Historiador que faz análise textual e lê nas entrelinhas, alcançando intuições e realizando inferências. Assim, pode-se afirmar que os relatos no início do XX, em geral, evidenciam 
que os viajantes estavam impregnados pelo pensamento que permeava a sociedade europeia como elemento de um espírito clássico, na expressão de Todorov, ou elemento do conceito de dispositivo, definido por Foucault. Era o tempo em que a antropologia continuava influenciada pelo positivismo e pelo darwinismo que, no caso italiano, era dizer Nicéforo e Lombroso, representantes do cientificismo que hierarquizava as raças.

Pesquisando desde 2001 nas principais bibliotecas de Turim, Gênova e Roma, encontrei 61 autores que privilegiam meu tema, isto é, a imigração italiana nas cidades brasileiras. No atual estágio da pesquisa faço um recorte temporal entre 1910 e 1925, período correspondente à ascensão do fascismo. São cinco os autores selecionados pela riqueza de dados que apresentam: D'Atri, Bianco, Bonacci, Carrara e Bartolotti.

Alessandro D'Atri pertence à nobreza italiana, um duque casado com brasileira, e exerce o jornalismo. No início do século reside em Paris, onde dirige a revista L'Italie illustrée. Viaja muito, funda vários jornais e revistas, colabora em inúmeras publicações. Em Nápoles já havia dirigido La Montagna, que contou com a colaboração de Bovio, Imbriani, Colajanni, expoentes da intelectualidade italiana no período. Entre as importantes obras que publicou encontram-se I Latini in America, La Giovane Italia a São Paulo. ${ }^{1}$

O livro analisado intitula-se Brasile faro de l'universo (D' Atri, 1910) e fornece dados preciosos sobre o Brasil na primeira década do século XX, à medida que, como outros viajantes, apresenta um estranhamento diante do inusitado, do exótico, ainda que sempre tendendo ao elogio.

Elogia cidades como o Recife, pelos seus hotéis que fazem inveja na Europa; clubes, bibliotecas, teatros, templos grandiosos, edifícios públicos majestosos, cafés, escolas, ricas casas comerciais, estabelecimentos industriais, refinarias de açúcar com maquinário aperfeiçoado. Uma universidade como não há na Itália, em amplo edifício de belas linhas arquitetônicas. Encontra um bem-estar na cidade que lhe fez prever um futuro de progresso para Pernambuco, lamentando que a Itália não estivesse fazendo parte daquele "banquete de prosperidade e riqueza". Acredita que os espíritos empreendedores italianos se arrependerão de abandonar iniciativas a outros capitalistas e à mão de obra de alemães, franceses e ingleses.

$\overline{1}$ Chi è. Dizionario degli Italiani d’oggi "Roma: Formiggini. 
Registra que, se a Cidade Baixa de Salvador conserva o aspecto desagradável das cidades portuguesas da época colonial, foi porque não recebeu o benefício da "luz projetada pelo renascimento italiano". Mas que, na parte alta da cidade, respira-se ar fresco, há modernos edifícios, largas ruas, praças com jardins. Quem fala mal do Brasil, escreve, está influenciado por interesses de países como Argentina e Venezuela, que brigam por imigrantes. Continua com elogios ao Espírito Santo, onde a imigração italiana estaria promovendo algum progresso.

Detém-se na beleza do Rio, nos elogios à cidade que considera moderna, com ruas espaçosas que cortam de uma praia à outra, inundando de luz os bairros industriais, uma enorme avenida beiramar, larga radiosa, rica. Destaca a Avenida Central e o dinamismo do ex-ministro Lauro Muller, de Pereira Passos, de Paulo de Frontin, do trabalho de saneamento de Oswaldo Cruz.

Acrescenta que, quando se dizia que a emigração era um dano, ele próprio defendia que fosse uma vantagem enorme para a economia da Itália e dos que emigravam. E que só mais tarde, quando as finanças italianas se refizeram pelo fruto do trabalho dos emigrados, os economistas e os que se diziam humanitários acabaram reconhecendo as vantagens.

Pergunta se o Rio de Janeiro, um dia, não será uma cidade mais sedutora que Paris, mais populosa que Londres, mais respeitável que Berlim, mais artística que Florença. Porque possui todos os elementos para tornar-se o centro de gravidade do pensamento do mundo, com taxas de mortalidade inferiores a Milão, Nápoles ou Roma.

Analisa a economia do estado de São Paulo, predizendo que a capital será a mais moderna, salubre, monumental das cidades da América Latina, suas indústrias farão dela a Manchester sul-americana.

Lembra que, quinze anos antes, havia observado uma bodeguinha como as encontradas nos lugarejos da Calábria, como dois queijos caccio-cavalli pendurados sobre a porta, anunciando a italianidade do bodegueiro, como uma bandeira. Dentro 5 vassouras, 4 caixas de querosene, 2 sacos de feijão, uns $10 \mathrm{~kg}$ de massa. $O$ bodegueiro não parecia satisfeito, sua mulher sofria pela miséria e pela saudade. Um menino sujo, quase nu, coberto de moscas, estava acocado em um canto. Um ano depois tentou passar defronte os caccio-cavalli. Não estavam mais na porta, mas dentro, em companhia de 14 formas de parmiggiano, dez barris de anchovas, macarrão, etc. A patroa exibia duas argolas de ouro nas orelhas e o patrão fumava um bom charuto. Voltou mais uma vez, três anos depois, e encontrou o bodegueiro ainda mais próspero; 
a mulher gorda, graças aos salames, ovos, mortadelas que se somavam aos gêneros já encontrados nos anos precedentes.

Arremata escrevendo que São Paulo é a bela, grandiosa e imponente cidade italiana da América Latina, prova luminosa do gênio italiano e do patriotismo dos paulistas. Desejaria que uma comissão de deputados italianos contrários à emigração viesse a SP, para observar como os seus conterrâneos podem empregar sua energia ativa e utilmente, em todos os ramos da vida industrial. Ali há um toscano que grita sua vitela para vender; um calabrês que anuncia seu queijo de Crotone feito em São Paulo, uma mantovana que vende verdura recomendando um tortei, um napolitano que agita uma tainha nas costas. No centro da cidade há grupos de jovens italianas em direção ao trabalho nas lojas de moda, manufaturas, bazares, armarinhos, camisarias.

Francesco Bianco é um jornalista romano, autor de L'Italia e il Brasile: la lotta dei giganti nell 'America del sud e la fortuna del mercato italiano, cujo título já diz bem a que veio. Também escreve Il Paese dell'avvenire (Bianco, 1908), o livro analisado, que se refere ao Brasil.

Começa dizendo que o Brasil é como a Bela Adormecida: um Príncipe virá para fazer brotar da terra as metrópoles opulentas; São Paulo já está em pleno desenvolvimento graças ao café; Rio de Janeiro é cidade cosmopolita, com opulenta vida mundana e grande atividade, onde há uma produção literária soberba.

Narra a chegada ao Rio do Deputado Orlando, ex-presidente do Conselho, embaixador extraordinário do Rei, em cujo Estado Maior encontra-se o Príncipe Aimone. Descreve a recepção solene patrocinada pelas autoridades brasileiras e por italianos residentes no Brasil. O mar em torno da navio estava repleto de barcos embandeirados, subiram a bordo os representantes oficiais da Presidência da República e outras autoridades. Os conacionais no Brasil encontravam-se com personalidades da história recente italiana; evidenciavam comoção e grande exaltação de sentimentos patrióticos na visita que pretende unificar a vastíssima coletividade italiana, assim como promover a concórdia. Ao meio-dia, o Príncipe Orlando desce à terra e saúda a multidão na praça. Afirma que os jornais interpretavam a visita como um grande acontecimento da política internacional, que o Embaixador Orlando trocou telegramas com o Rei Alberto da Bélgica, que partira na véspera do Rio de Janeiro. Assinala a recepção oferecida pelo Presidente Epitácio Pessoa, logo no dia da chegada da comitiva, assim como registra as homenagens do Parlamento brasileiro. Entretanto, o jornalista lamenta que haja propaganda negativa ao Brasil na Itália e na Itália contra o Brasil. 
Segundo Bianco, a viagem que narrava visara realizar um estudo da totalidade dos interesses entre os dois países. Orlando na ocasião afirmara a superioridade dos vínculos intelectuais aos econômicos, propondo colaboração intelectual entre universidades dos dois países e a vinda ao Brasil de professores universitários italianos. Lembra que o Jornal do Comércio elogiara a proposta, para que a Itália recuperasse terreno, dada a supremacia da força da cultura alemã e francesa no Brasil, assim como o esforço da propaganda norte-americana. Afinal, braços italianos emigravam, mas os intelectuais ficavam na Itália, à sombra dos seus campanários.

Mas é a discussão econômica que realmente ocupa várias páginas. Comenta sobre o comércio italiano, as atividades econômicas em geral na Península; nas entrelinhas percebe-se o esforço de organização empreendido pelo Cônsul Sola, que organiza reuniões com dirigentes de instituições e com expoentes da coletividade, como o Cavaliere Sciutto, importador na praça do Rio. Lê-se lamentos quanto à guerra comercial em desenvolvimento, visto que a Itália se encontra em desvantagem, também porque concorrentes denigrem a imagem do país. Ademais, Bianco sublinha que o comércio italiano no Brasil não recebe qualquer apoio, que as comunicações são deficientes entre os dois países e que a Itália não tem agências telegráficas no exterior.

Um terceiro viajante emblemático do período é Giovanni Bonacci. Bonacci, de quem não foram encontrados dados biográficos. Sabe-se apenas que escreveu L'Italia vittoriosa e la sua espansione nel mondo. Nel Brasile (Bonacci, 1920).

Já no prefácio registra que, feito o armistício, em 1918, Pogliani abrira filiais do Banco de Descontos em cidades brasileiras, demonstrando que, depois da vitória, uma expansão da Itália no mundo estava sendo promovida e que havia uma atenção especial com o Brasil, país aberto à civilidade dos italianos, cujo trabalho trouxera contribuição tão importante quanto aquele de outras nacionalidades. País extenso, com abundância de riquezas naturais, onde experiências recentes demonstravam a existência de carvão com enorme força hidroelétrica. Diz que no Brasil não fazia nem muito frio nem muito calor, sendo o país superior à China, ao Canadá, aos Estados Unidos.

Conforme o autor, o Brasil representava um ponto intermediário para a comunicação entre as repúblicas sul-americanas e o Atlântico, encontrava-se em ascensão, visto que o desenvolvimento norteamericano teria chegado ao apogeu, permanecendo estacionário. Lembra que Eliseo Reclus, antes da proclamação da república brasileira, 
escrevera que o Brasil tinha todas as vantagens naturais, era uma terra prometida; também lembra Clemenceau que, em 1910 e depois de uma viagem ao Brasil, escrevera inúmeras páginas de admiração pelo país.

Diz que, além dos elogios, o Brasil recebera da França vários milhares empregados para as ferrovias. Que o Japão organizava frota mercantil potente para negociar com o Brasil; que a Inglaterra e os Estados Unidos faziam esforços para dominar a produção e a vida econômica: Armour, de Chicago, implanta frigoríficos; Frederic Mason, enviado pelos economistas norte-americanos, aconselha uma maior confiança no Brasil. Junte-se a isso o fato de que os italianos tem maiores possibilidades de sucesso no Brasil, porque vivem aqui em grande número. Até mesmo os agentes do City Bank recomendavam empregar-se agentes italianos para obter sucesso no comércio; antes da guerra, cinco casas comerciais vendiam anilina alemã em São Paulo, quatro eram representadas por italianos e duas por suíços de lingua italiana, uma escolha feita a propósito, porque quem fala italiano aprende logo o português.

Ao contrário do que diziam os viajantes de décadas anteriores, afirma Bonacci que, no Brasil, o italiano é fraternamente amado, admirado, desejado; que o estado de São Paulo é o mais próspero porque acolheu dois terços dos italianos no Brasil; que Epitácio Pessoa irmanou-se com os sentimentos italianos quando de sua visita a Roma, a exemplo de todos os brasileiros.

Comenta a opinião de Altino Arantes, presidente do Estado de SP, quando diz que o mesmo estado deve à Itália um patrimônio moral e a prosperidade econômica. Assinala que o Dr. Souza Dantas, embaixador junto ao Quirinal, afirmava que o Brasil é grande graças à Itália e aos italianos. E lembra que, nos treze meses em que esteve no Brasil, testemunhou a admiração das autoridades pelas múltiplas atividades desenvolvidas no país por italianos.

Detém-se em São Paulo, assinalando que o Brasil meridional é a sede da prosperidade do país e que tem boa organização financeira: impulsiona o país com a grande indústria e as vias de comunicação. A cidade de São Paulo teria para o autor três quartos da população italiana; o prefeito Washington Luiz transformara a cidade, construindo ruas semelhantes ao Corso Vittorio Emanuele de Roma ou a Via Manzoni de Milão. Lembra o Prof. Bertarelli, que teve longa permanência no Brasil, pelos elogios que fizera aos novos bairros e avenidas, como a Avenida Higienópolis, com palacetes belíssimos, jardins; lembra também 
a afirmação de que em São Paulo havia baixa taxa de mortalidade, baixíssima mesmo quanto à tuberculose.

Domenico Bartolotti foi escritor especializado em Política e em Direito, considerado crítico competente das questões referentes às colônias. Publicou: Il passato e l'avvenire della Tripolitania; L'utopia della Società delle Nazioni e della pace bellica. ${ }^{2}$ Escreveu também Il Brasile, que foi o livro analisado (Bartolotti, 1926).

Visita o Rio de Janeiro por ocasião das celebrações do primeiro centenário da Independência do Brasil, reconhecendo que o país oferece prova de consciência política, é Estado indivisível e a exposição comemorativa que assiste demonstra excepcional desenvolvimento industrial, exemplificando com o Pavilhão das Indústrias Reunidas Matarazzo. Não economiza elogios ao descrever as obras colossais realizadas na capital brasileira, como a Avenida Rio Branco e o Palácio Monroe.

Avalia os pavilhões da exposição, considerando notáveis prédios aqueles da Argentina, Inglaterra e Japão. Atribui primordial destaque ao pavilhão norte-americano e, pela importância da mostra, destaca os pavilhões da Bélgica e da Dinamarca, qualificando de modesto o pavilhão da França. Define como, ao menos, digno aquele pavilhão instalado pela Itália, apesar da impropriedade de certos artigos expostos. Elogia o ambiente cosmopolita da exposição, sobretudo pelo ponto de encontro situado no Palácio das Festas e pelas inúmeras diversões à disposição dos visitantes. Releva a figura do Conde Francesco Matarazzo, comentando que há imigrantes que são um produto da seleção natural.

Outra obra sua encontrada intitula-se Il Brasile Meridionale (Bartolotti, sd). Nela descreve a chegada das primeiras cem famílias italianas no RJ, em 1875; o grupo com 50 imigrantes, dirigido pela Adelina Malavasi, que foi direcionado às colônias de Santa Catarina. Destaca personalidades da colônia italiana no Rio de Janeiro, como os Farani que foram dos primeiros na cidade, a cantora Besanzoni, casada com o rico armador Lage. Menciona a sociedade de socorros mútuos, o Centro italiano d'Istruzione, fundado pelo ex-embaixador Antonelli; dentre outras sociedades existentes. Discorre sobre Porto Alegre, Pelotas, Santa Maria e Rio Grande, elogiando a importância desse porto de mar.

2 Archivio Biografico Italiano Microfilmato. Biblioteca Centrale di Roma. ROVITO, Teodoro. "Letterati e giornalisti italiani contemporanei", 1922. 
Enrico Carrara (1925) escreveu Ventotto porti dell'America Latina: fra Atlantico e Pacifico con la nave 'Italia'. Trata-se de um engenheiro, nascido em Reggio Emilia, em 1871. Participa do famoso cruzeiro patrocinado pelo governo italiano, comitês e câmaras de comércio, para analisar as condições políticas, econômicas e sociais dos diversos países da América central e da América do Sul, expondo produtos italianos. ${ }^{3}$ Esclarece no prefácio que a Nave "Italia", em 8 meses, visitou 28 portos, 40 cidades de 13 países sul-americanos e da América Central. Lamenta que o tempo tenha sido pouco, 8 ou 10 dias em cada país, e que sua visão dos lugares visitados é panorâmica e sincrônica.

Segundo o engenheiro, nos portos principais, representantes diplomáticos e adidos comerciais ingleses, franceses, alemães e norteamericanos interrogavam e observavam, possivelmente admirados porque a primeira nação a ter a iniciativa de organizar uma nave exposição foi a Itália. O Embaixador extraordinário nomeado para o cruzeiro foi o Sr. Giuriati.

Afirma que seu livro destina-se a contribuir para transformar o ponto de vista de que América do Norte é desenvolvida, enquanto América do Sul é insalubre, socialmente atrasada. Menciona mudanças no pós-guerra; que há cidades pouco conhecidas na Itália que são modernas, como Recife, com serviços públicos organizados e com vida social digna de cidades europeias. Há também enormes extensões por cultivar, minérios intocados e necessidade de imigrantes. Os italianos são preferidos, por sóbrios, trabalhadores e facilmente assimiláveis, último matributo que o autor muito lamenta. Acredita que seria bem acolhida uma emigração organizada e enquadrada com maquinário, engenheiros, enfim uma emigração já pronta, organizada por iniciativa de grandes empresários .

Descreve a chegada em Belém, dizendo que a cidade acolhe bem, que ao encontro do navio vêm cinco ou seis vaporzinhos com bandeira italiana; tocam sirenes e do grupo de homens de branco e de senhores elegantes ouve-se vivas à Itália. A colônia italiana ali é pouco numerosa, mas ativa: cerca de 450 pessoas todas presentes à recepção, além dos cidadãos paraenses que formavam um público exultante. Esclarece que o progresso de Belém deve-se à borracha, que são moderníssimas as docas no porto, que se perdem de vista. É próspero o pequeno comércio de madeira raras e os viajantes são sempre recebidos com cordialidade; participou de recepções para homenagear os visitantes no Pará Clube e

\footnotetext{
3 Chi è? Dizionario degli italiani d'oggi.
} 
no Palácio do Governador. Aprecia o guaraná e sugere que seja lançado na Itália como bebida.

No Rio de Janeiro chegam em meio a uma saudação que vem da terra, gritada pelo embaixador Badoglio, enquanto o navio é invadido por autoridades e jornalistas. Um trem conduziu à residência presidencial em Petrópolis, cidade serrana frequentada pela elite durante o verão, apenas mantendo um antigo costume, pois o Rio de Janeiro tornou-se uma das mais sadias capitais do mundo. No Rio realizou-se um coláquio entre o embaixador Giurati, o presidente Artur Bernardes e o Ministro do Exterior Felix Pacheco; foram examinadas as condições da colônia italiana no Brasil e a possibilidade de enviar novos imigrantes. Giurati parecia barganhar, dizendo que o agricultor na Itália então tinha o que comer e, para emigrar, precisaria ser compensado com notável rendimento.

Carrara admirou-se com a exposição bélica do Rio de Janeiro, quando um tanque de guerra Fiat, com suas metralhadoras, foi apresentado ao Ministro da Guerra do Brasil. Outra metralhadora foi experimentada num maravilhoso quartel que domina o mar e a baía de Guanabara; disparou 750 tiros consecutivos, fazendo a alegria do Coronel Invernizzi e do Capitão Boccalaro, responsáveis pela demonstração. O autor assinala que isto acontecia justamente quando a missão francesa se encontrava no Brasil, para a instrução do exército, graças à negligência de um ministro italiano. Registra que também os franceses ficaram estupefatos com o armamento italiano.

Elogiou o concerto realizado pelo trio Bufaletti, Bonucci e Serrato, tendo o público resistido ao pesado programa, por duas horas em silêncio. Registra que os brasileiros descrevem São Paulo como a locomotiva; maquinistas e foguistas são os italianos ou seus descendentes. Diz que não há ramo de atividade ou movimento social em que não prevaleça a raça e a língua italiana. O Presidente do Estado, Carlos de Campos, em banquete oficial, afirma que as maiores empresas industriais são de italianos, assim como os bancos, e o poderoso proletariado, que trabalha irmanado ao nacional.

Destaca como modelar uma instituição penal: a de Sant'Ana, que acolhe até 1200 condenados, construída por engenheiro italiano, conforme a antropologia criminal lombrosiana; o estabecimento possui repartição antropométrica, com fotografias, digitais e molde dentário de cada detento.

Na última década do século XIX, primeira década republicana, milhares de imigrantes haviam chegado ao Brasil, auxiliando no 
crescimento das cidades e colonizando amplas regiões do país. Tais fluxos imigratórios teriam continuidade até 1914, quando findou a Primeira Guerra Mundial.

Naquele período, a Itália encontrava-se esgotada: moeda sem valor, empobrecimento notável das camadas populares, tensão na cidade e no campo. Enfim, uma conjuntura propícia à ascensão do fascismo que permaneceria vinte e três anos no poder, desde 1922, apoiado de início pela maioria, inclusive por intelectuais que acreditavam fosse o regime a reanimação das ideias mazzinianas. Tais ideias, adaptadas a outro contexto, estiveram acompanhadas pelo radicalismo nacionalista, pelo fortalecimento do mito da Roma Imperial, pela valorização dos feitos dos navegadores italianos, pela glorificação da arte, da filosofia e da literatura do pensamento renascentista. Neste contexto decididamente não cabia o fenômeno da imigração, sempre acompanhado pela pobreza, abandono, doença, exploração. Enfim, a emigração e os emigrantes representavam uma imagem indesejada para um país que se pretendia organizado e moderno. Tornava-se necessário disfarçar, maquiar a imigração; muitos esforços foram feitos neste sentido, a começar pela reorganização da estrutura diplomática e consular, para que atuasse no exterior fortalecendo o fascismo.

A ideia de uma imigração tutelada se impõe, com a finalidade de divulgar a ideologia junto aos imigrantes para que mantivessem firmes os proveitosos vínculos com a pátria-mãe, como escreve Ianni, (1963, p. 117). Implantava-se uma reforma na estrutura diplomática e consular, centralizando os fasci de modo que dependessem dos representantes italianos no exterior, isto é, embaixadores e cônsules, que deveriam reforçar a propaganda do fascismo e dos feitos de Mussolini. Lembra Camerana que tornou-se "[...] necessário abolir a palavra emigrante e substituí-la pela expressão italiano no exterior". Teria sido este o principal slogan da diplomacia de Mussolini (Di Camerana, 2002, p. 474).

Todos os viajantes analisados elogiam nossas cidades e detacam a obra de italianos no progresso das mesmas, predizendo grande futuro ao Brasil. Sobre imigrantes, há exemplo emblemático apresentado por D'Atri, quando lembra a rápida prosperidade do casal proprietário de armazém que, através de caccio-cavalli, exibe sua italianidade.

Bianco exalta a recepção solene ao Deputado Orlando, que depois chegou a ser Primeiro Ministro; no seu Estado Maior estava o Príncipe 
Aimone ${ }^{4}$, representando a Casa de Savóia. O autor descreve essa recepção por parte das autoridades e de italianos residentes no Brasil, comovidos e em patriótica exaltação. Mas é a discussão econômica que ocupa várias páginas, com lamentos pela desvantagem italiana na guerra comercial.

$\mathrm{Na}$ economia centra-se Bonacci, enfatizando a expansão bancária italiana no pós-guerra. Destaca as potencialidades brasileiras e as vantagens da presença italiana no Brasil, onde o italiano é admirado e desejado. O mesmo faz Carrara, esclarecendo sobre a visita que a nave Itália faz ao Brasil, a primeira nave organizada com caráter de uma exposição, trazendo a bordo inúmeras personalidades e até mesmo um embaixador extraordinário da Itália para os países visitados. Visita o Rio de Janeiro por ocasião das celebrações do primeiro centenário da Independência do Brasil, assinalando a vida associativa dos italianos.

Eloquentes serão os fragmentos de filme realizado quando a nave Itália alcança o porto de Rio Grande em 1924. Nave vitrine da Itália, representa muito bem a política diplomática agressiva de Mussolini, com uma mostra da arte e da produção italiana; vidros de Murano, tecidos, óculos, esculturas, pavimentos, motores de aviação, automóveis, rendas e lavadoras elétricas, além da reprodução da cela em que dormia Dante, uma sala do século XIV, uma capela transplantada de Firenze. ${ }^{5}$

A Itália de Mussolini tratava de construir nova representação, vigorosamente divulgada pela ação diplomática: era a imagem dos operosos cidadãos italianos no exterior, tributários de uma valorosa pátria-mãe, como sugerem os nossos viajantes, que expressam à perfeição a mentalidade que se impunha na Itália fascista, assim como as transformações que se verificavam no Brasil. Os imigrantes começavam recém a serem reconhecidos como homens e mulheres capazes de contribuir para a economia italiana.

\section{Referências}

BARTOLOTTI, Domenico. Il Brasile meridionale. Roma: Casa Editrice Alberto Stock, [s.d.].

BARTOLOTTI, Domenico. Il Brasile. Gênova: SIAG, 1926.

4 O príncipe Aimone Roberto Margherita Maria Juan Torino, quarto Duque de Aosta, nasceu em 9 de março de 1900 em Turim. Foi o segundo filho do príncipe Manuel Filiberto, segundo Duque de Aosta e da princesa Helena. Seu bisavô foi o rei Victor Emanuel II de Itália.

5 Sartorio - 1924: Crociera della Regi Nave "Itália" nell America Latina. Roma: Istituto ItaloLatino Americano, 2000 
BIANCO, Francesco. L'Italia e il Brasile: la lotta dei giganti nell'America del sud e la fortuna del mercato italiano. Milão: Mondadori, 1908.

BONACCI, Giovanni. L'Italia vittoriosa e la sua espansione nel mondo. Nel Brasile. Roma: a Banca Italiana Sconto, 1920.

CARDOSO, Sérgio. O olhar dos viajantes. In: NOVAES, Adauto et al. O Olhar. São Paulo: Companhia das Letras, 1988.

CARRARA, Enrico. Ventotto porti dell'America Latina: fra Atlantico e Pacifico con la nave 'Italia'. Torino: Alberto Giani Editrice, 1925.

CATTARULLA, Camilla. Alla "riscoperta"del nuovo mondo-1. In: Biblioteche Oggi, n. 4 e 5, 1992.

Chi è? Dizionario degli italiani d'oggi. Roma: Formiggini.

D'ATRI, Alessandro. Brasile faro de l'universo. Paris, 1910.

DI CAMERANA, Ludovico Incisa. La diplomazia. In: BEVILACQUA, Piero et al. Storia dell'emigrazione italiana: arrivi. Roma: Donzelli, 2002.

IANNI, Constantino. Homens sem paz: os conflitos e os bastidores da imigração italiana. São Paulo: Difusão Europeia do Livro, 1963.

LEED, Eric J. La mente Del viaggiatore: dall'Odissea al turismo globale. Bologna: Il Mulino, 1992.

LOMONACO, Dott. Alfonso. Al Brasile. Milano: Società Editrice Libraria, 1889.

MACOLA, Ferruccio. L'Europa alla conquista dell'America Latina. Veneza: Ferdinando Ongania Editore, 1894.

MORICONI, Ubaldo. Nel Paese de "macacchi”. Torino: Roux Frassati e Co. Editori, 1897.

ROVITO, Teodoro. Letterati e giornalisti italiani contemporanei. 1922.

Sartorio - 1924: Crociera della Regi Nave “Itália” nell'America Latina. Roma: Istituto Italo-Latino Americano, 2000.

TRENTO, Angelo. Do outro lado do Atlântico: um século de imigração italiana no Brasil. São Paulo: Nobel; Istituto Italiano di Cultura di San Paolo; Instituto ÍtaloBrasileiro, 1988.

\section{Fonte:}

Archivio Biografico Italiano Microfilmato. Biblioteca Centrale di Roma. 